\title{
A Survey Paper on Leave Automation
}

\section{Snehal Vijay Kamble, Amruta Shivaji Kamble, Priyanka Sanjeev Babar, Sushmita Shrimant Kakmare, Mr. Nilesh D. Ghorpode}

Sanjay Ghodawat Polytechnic, Maharashtra, India

\begin{abstract}
In the existing Leave Automation Record, every College/ Department follows manual procedure in which collage faculty enters information in a record book. At the end of each month, Administration Department calculates leave/s of every faculty which is a more time taking process and there are chances of losing data or errors in the records.
\end{abstract}

This module is a single leave automation that is critical for HR tasks and keeps the record of virtual information regarding leaves. It intelligently adapts to HR policy of the automation and allows employees and their line managers to manage leaves and replacements (if required). In this module, Head of Department (HOD) will have permissions to look after data of every faculty member of their department. HOD can approve leave through this application and can view leave information of every individual.

This system can be used in a college to reduce processing work load. This project's main idea is to develop an online centralized application connected to database which will maintain faculty leaves and their replacements (if needed). Proposed System will reduce paperwork and maintain record in a more efficient \& systematic way. This module will also help to calculate the number of leaves taken monthly/annually and help gather data with respect to number of leaves, thereby helping in calculating the leaves working days by the HR Department.

Keywords: leave automation, leave management

\section{INTRODUCTION}

This project is aimed at developing an online leave automation that is of importance for smooth functioning of organization. The Leave automation is an Intranet based application that can be accessed throughout the organization or a specified group/Dept. This system can be used to automate the workflow of leave system and their approvals. The periodic crediting of leave is also automated. There are features like notifications, automatic approval of leave, report generators etc. in this system. Proposed System will reduce paper work and maintains record in more efficient way.

In the existing paper work related to leave system, leaves are maintained using the attendance register for staff. The faculty needs to submit their leaves manually to their respective authorities. This increases the paperwork \& maintaining the records becomes tedious. The main objective of the proposed system is to decrease the paperwork and help in easier record maintenance by having a particular centralized Database System, where Leaves and Notices are maintained. The proposed system automates the existing system. It decreases the paperwork and enables easier record maintenance. It also reduces chances of Data loss.This module intelligently adapts to HR policy of the management \&allows employees and their line managers to manage leaves and replacements forbetter scheduling of workload. The application basically given modules:

\section{Literature Review-}

The literature review and project methodology is a chapter that describes the analysis and findings on passed research, case study or research that relates with this project, selected approach or methodology used in this system detail.

\section{EXISTING SYSTEM:}

In existing system every college follows manual procedure in which the faculty needs to submit leave application to HOD and after getting approval from HOD, faculty member submit application to HR department. And after thoroughly checking by HR department the faculty will come into know about their leave status. The existing process is manual and time consuming.

\section{PROPOSED SYSTEM:}

In proposed system the faculty members are having their own user account by which they can apply for leave with proper load adjustments. HOD will get notification in their login about needs of leave for any staff. HOD as per his rights can sanction or de sanction leave for staff and staff will get notification for the same. Further HR department will also get intimation about leaves and as per their right they can sanction or de sanction leave for staff. The proposed system is online module due to which chances of losing data is not possible because data is maintained in the form of database. Every day leaves information is updated in to database using a user friendly. This will reduce work load for Head of departments Staff,HR. This system is an online system which makes more flexible to access information.

\section{MODULE DESCRIPTION:}

Number of Modules After careful analysis the system has been identified to have the following modules in this system:

1. Staff Module

2. HOD Module

3. HR Module

4. Principal Module

\section{Staff Module}

In staff module staffs are having their own user accounts by which they can apply for various leaves like Casual, Medical 


\section{HOD Module}

In HOD module HOD gets information about staff leaves and they can allow or deny leaves of Staff.

\section{HR Module}

In this module HR department can add, modify \& delete staff along with no of leaves types of leaves for respective staff.

\section{Principal Module}

Principal can view Informationof every department's faculty information and take action based on the leaves .Principle can view information like faculty member's leaves

\section{Objectives and Scope-}

\section{$>$ Objective}

To automate the existing leave management in educational institutes to decrease the paperwork and enable the process with efficient, reliable record maintenance by using centralized database, thereby reducing chances of data loss. To provide for an automated leave system that intelligently adapts to HR policy of the organization and allows employees and their line managers to manage leaves and replacements for better scheduling of work load \& processes. develop later.Many analyses must be done to know the business process of the as is system and to-be system. Analysis about requirement and functionality of the system is very important in process to develop the system.

\section{Design Phases}

Based on the analysis phase, the design will be done. The design phase is consisting of 3 activities. The activities are:

\section{A. Logical design}

This activity involves class diagram and interaction diagram.

\section{B. Interface design}

The activity includes navigation design, output design and input design.

\section{Database design}

This activity defines logical data model, detail explanation for each entity, description of the association, cardinality and relationship.

\section{Testing Phase}

In this phase, the all functionality system are testing and confirm that there are no error and record the entire not function requirement and correct it.

\section{Implement Phase}

After all phase have been perfectly done, the system will be implemented to the server and the system can be used. the given session can be automatically carried forward to the next working session depending on the HR policy of the organization.

$>$ Every employees individual leave record can be tabulated in are port format to a certain his/her performance during the working session for $\mathrm{HR}$ appraisal activity.

$>$ The summarized data generated by this system can be further provided to different departments.

$>$ If personal data is fed into the system while creating employee profiles, a single interface to ascertain information such as no. of years worked, birthdays, notice period, promotions, can be availed at a single point by the HOD.

\section{Methodology- \\ I. Planning Phase}

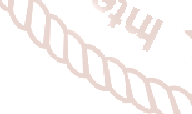

In this phase, the first step is making a research in detection the best project to propose. After get information about the project, propose is submitted. The proposal consists of the project background, problem area, objectives and project requirements. This is the most important thing to do in phase planning.

Besides that, the faculty has accommodated a flow that need to be follow by the student. From the schedule, the student can plan the best method in managing time to develop the project. Grant chart are develop base on schedule and time that given by the lecturer to submit those entire thing needed.

\section{Analysis Phase}

First of all, the analysis has to done to know the view of whole system to develop. The content of the proposal is the result from the analysis. In this, the important thing need is make more research to captured key functionality, system process and tools needed. This finding and researches can be done via internet, journal, books and article. The finding should be described and elaborate in diagram, chart and table to make the system easier to understand in process of

\section{Section of methodology}

Project Management Methodology consists of five stages:

$>$ Initiating

$>$ Planning

$>$ Executing

$>$ Controlling

$>$ Closing

\section{Implementation plans}

In this phase is starting at process installing software requirements. Installation hardware is setting up the server hardware requirements needed. Then, the operating system installation, which is XAMMP installing required.

\section{Management Plan}

In-charges and approver are encouraged to work with all employees who have added extra leave to develop an excess Employee Leave Management Plan to reduce the liability. An the employee and employer that designates actions for reducing excess leave accrual in a timely manner. This may involve setting leave dates, managing for a cash payment of leave, or formally deferring leave (all subject to Industrial Agreement/Award conditions). An Employee Leave Management Plan must also take into consideration the additional leave that will fall due during the ELMP timeframe.

\section{Employee:}

$>$ Faculty can apply for leave to the system

$>$ System will send a mail to Approver and Faculty

$>$ See number of day when apply for leave after all deduction of public holiday and official holiday

$>$ Able to calculate total, applied/ pending, Approved and balanced leaves for each leave type Employee Leave Management Plan is an agreement between 
International Journal of Trend in Scientific Research and Development (IJTSRD) @ www.ijtsrd.com eISSN: 2456-6470

$>$ Have to input from date, to date, leave type, reason, description and his/her approver

\section{Approver:}

$>$ Approver can see a leave requests as a list

$>$ After his approval he will got a mail also the applicant of the leave request

$>$ Add leave type

$>$ Add Leave Reason

$>$ Add public holiday

Department In-charge: - He will approve after approval of approver.

\subsection{BLOCK DIAGRAM:}

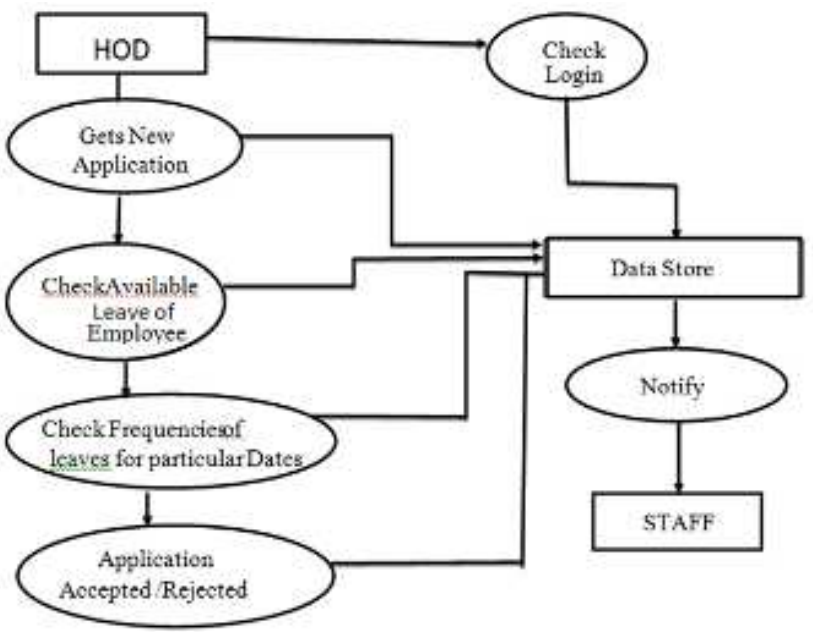

Block Diagram1: HOD Module

\subsection{FLOW CHART:}

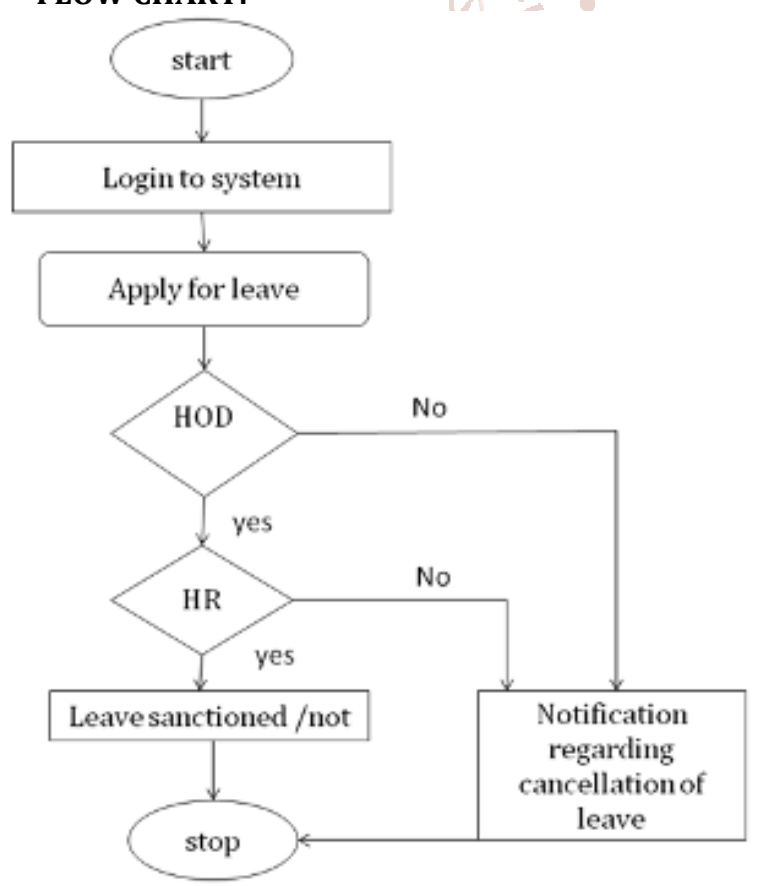

Flow Chart1: Staff module
4.5 DATA FLOW DIAGRAM:

4.5.1 DFD Level 0-

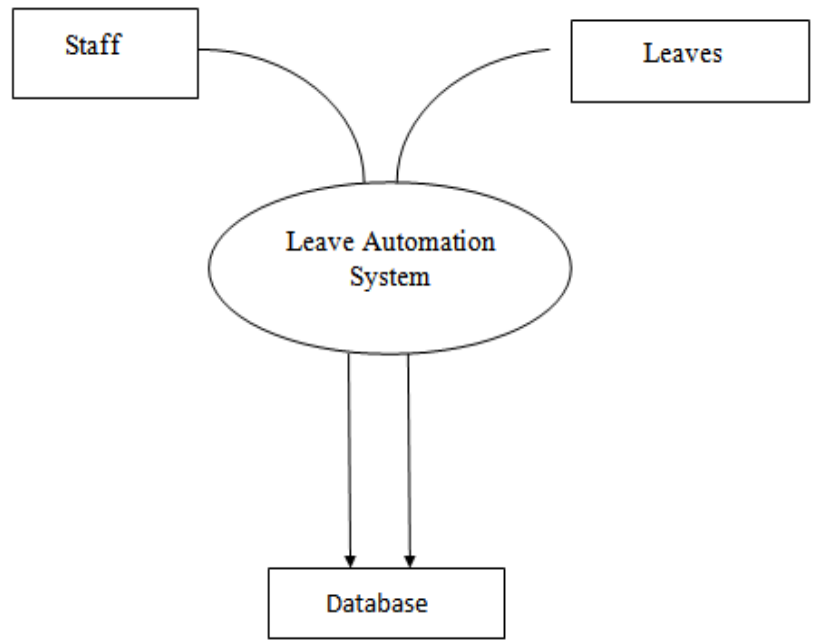

4.5.2 DFD Level 1-

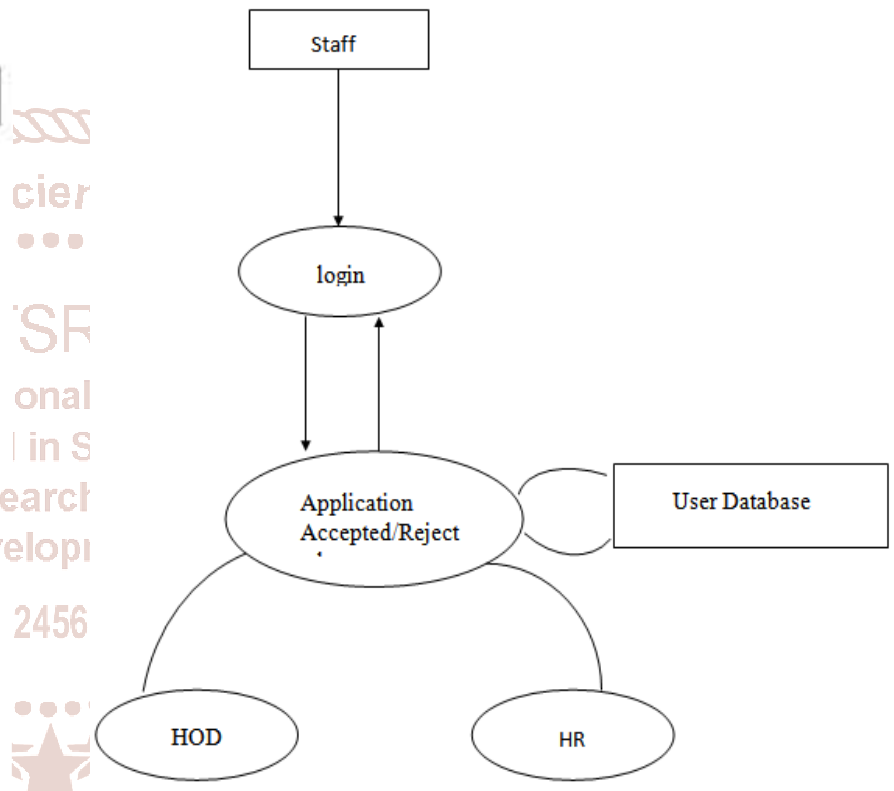

4.5.3 DFD Level 2-

4.5.3.1 Admin:

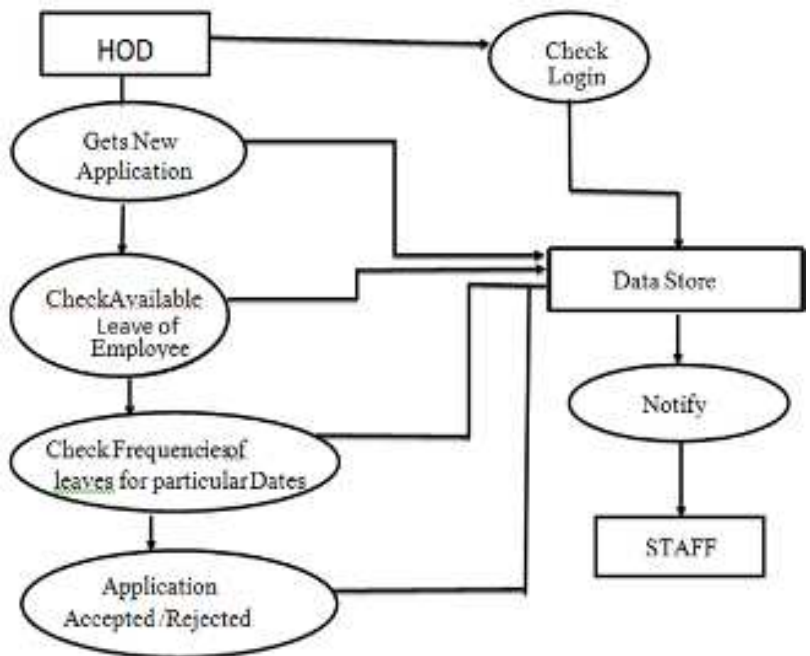




\subsubsection{Staff:}

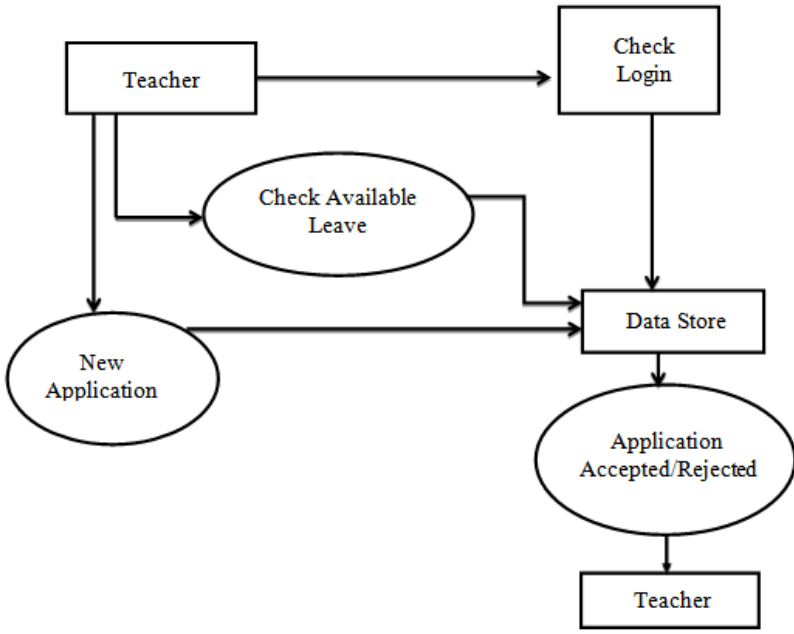

5. Advantages:

$>$ Eliminates the use of paper leave application forms.

$>$ Is cost efficient.

$>$ Provides GUI and Digitalization.

$>$ Easy to maintain in Centralized Database.

$>$ Leave applications can be submitted via network.
$>$ Leave application can be approved easily and notified to respective staff

$>$ Both the leave applicant as well as the approver can view the balance leave and past leave application.

$>$ Calculate the number of leaves taken on monthly/yearly basis.

\section{Conclusion:}

Further upgradation of the Leave Management System for various types of organizations with multiple hierarchies can help in reducing paperwork, help achieve error free tabulation and calculation of leaves.

\section{References:}

Websites:-

[1] www.w3school.com

[2] www.tutorialspoint.com

[3] http://msdn.microsoft.com

\section{Books:-}

[1] Murach's PHP and MySQL

[2] The JOY of PHP by Alan Forbes

[3] Fifth Edition PHP and MYSQL by kevin yank 